\title{
Identification, Management and Ten-Year Follow Up of Chronic Hepatitis B Virus Infection among Filipino Children
}

\author{
Germana V. Gregorio, Elizabeth G. Martinez and Jossie M. Rogacion \\ Section of Pediatric Gastroenterology, Hepatology and Nutrition, College of Medicine and \\ Philippine General Hospital, University of the Philippines Manila
}

\begin{abstract}
Background. There is no local study on the features of childhood chronic Hepatitis B virus (HBV) infection. This information is important to increase awareness of the disease and in making therapeutic decisions.
\end{abstract}

Objectives. To determine the clinical, biochemical, histological features and outcome of chronic HBV infection among Filipino children and to assess the effect of anti-viral treatment.

Methods. Prospective cohort study which included patients $<19$ years old positive for HBV DNA, HBeAg and HBsAg for at least 6 months. Clinical, biochemical, virological and histological evaluations were done. The outcome of the patient and effect of anti-viral treatment were assessed.

Results. Thirty six (36) patients [median (range) age: 9 (0.7-17) years; $64 \%$ males] were included and monitored from 1 to 10 years (median: 5). Majority (69\%) had vertical transmission. All were asymptomatic. Elevation of transaminase levels was observed in $5(14 \%)$ patients. Fifteen of $28(54 \%)$ patients had minimal portal tract inflammation. One patient developed cirrhosis. Sustained HBeAg clearance was seen in 6/14 (43\%) interferon- $\alpha$ treated and $2 / 22$ (9\%) untreated patients.

Conclusions. Perinatal transmission is the most common route of chronic HBV among Filipino children. All patients were asymptomatic with almost normal liver function tests. Majority had morphologically mild liver disease. In limited cases, treatment accelerated $\mathrm{HBeAg}$ clearance.

Key Words: perinatal transmission, portal inflammation, interferon

\section{Introduction}

Chronic Hepatitis B virus (HBV) infection is a major public health problem with an estimated two billion people worldwide infected with the virus. There is uneven prevalence throughout the world, with the Philippines considered highly endemic with a $6-12 \%$ hepatitis B surface

Corresponding author: Germana V. Gregorio, MD

Department of Pediatrics

Philippine General Hospital

University of the Philippines Manila

Taft Avenue, Ermita, Manila 1000 Philippines

Telephone: +6325240892

Email: germana1@hotmail.com antigen (HBsAg) prevalence rate similar to China and other countries in Southeast Asia and Sub-Saharan Africa. ${ }^{1}$ Perinatal infection accounts for $40 \%$ of HBsAg carrier rate in Asia, while in Africa, the majority of infections are acquired between 6 months to 6 years of age (horizontal transmission). In a survey of 533 Filipino asymptomatic pregnant women, the overall HBsAg positivity was $9 \%$, of whom $17 \%$ were hepatitis B ' $\mathrm{e}$ ' antigen (HBeAg) positive. ${ }^{2}$ Seroepidemiological studies of 1500 Filipino children aged $<1$ to 19 years showed that $12 \%$ are HBsAg positive. ${ }^{3}$ Although the majority of these children are asymptomatic, these 'healthy' HBsAg positive carriers constitute an important reservoir of the virus and carry a $25 \%$ lifetime risk of developing cirrhosis and hepatocellular carcinoma, therefore, the need to eradicate the virus. ${ }^{4}$

Among the viral agents, interferon alpha (IFN- $\alpha$ ) and lamivudine have been widely used in children for the treatment of chronic HBV infection, with a higher HBeAg clearance and anti-HBe seroconversion rate with IFN- $\alpha .5,6$ Several clinical trials ${ }^{5}$ reported a 30 to $50 \%$ response rate with IFN- $\alpha$ as compared to $23 \%$ in Lamivudine treated patients. A high pretreatment transaminase level, which probably reflects an attempt by the host's immune system to eliminate infected hepatocytes, has also been identified as an important predictor of a successful outcome with treatment. Other studies however did not show differences in response rate according to basal transaminases. ${ }^{7,8}$

In the Philippines, no study has reported the clinical features, the biochemical and histological activity of liver disease, and the outcome of children with chronic HBV infection. A careful understanding of the demographic and natural history of chronic $\mathrm{HBV}$ is important in order to heighten the awareness of the physicians regarding the disease and in making decisions regarding treatment. The objectives of this study are to determine the clinical, biochemical, virological, histological features and outcome of liver disease among Filipino children with chronic HBV infection and to assess the effect of anti-viral treatment among patients who were given the drug.

\section{Methods}

This prospective cohort study was conducted at the Section of Pediatric Gastroenterology, Hepatology and 
Nutrition of the Department of Pediatrics, University of the Philippines Manila Philippine General Hospital from 20002010. The approval of the ethics committee of the Institution was obtained before commencement of the study.

Consecutive patients less than 19 years of age who were positive for HBV DNA, HBeAg and HBsAg for at least 6 months were included. On admission, a full clinical history including demographic, pretreatment clinical data and medical history was taken. A general examination was performed and signs of chronic liver disease was sought including hepatomegaly, splenomegaly and cutaneous features of liver disease. As part of routine investigations for chronic HBV patients, liver function tests for aspartate (AST), alanine transaminase (ALT), albumin and prothrombin time were determined and an ultrasound of the liver and hepatobiliary tract was done. A liver biopsy was also performed, if possible, to determine the stage of the disease and degree of inflammatory activity classified as minimal, mild, moderate or severe chronic hepatitis. ${ }^{9}$ The specimens were stained with hematoxylin and eosin and were interpreted by a single pediatric histopathologist.

Subsequent assessments for general well-being, transaminase levels and $\mathrm{HBe}$ and $\mathrm{HBsAg}$ determination were conducted every six to 12 months up to at least 24 months with annual ultrasound and alpha feto protein monitoring. If the parents decide that their children undergo antiviral treatment, they were monitored more closely for any side effects of the drugs. Response to treatment was assessed by sustained clearance for one year of the HBeAg on two occasions, and if possible, a repeat HBV DNA determination.

The data were expressed using descriptive statistics and presented in median (range) and number (percentages).

\section{Results}

A total of 36 patients were included in the study with a median age of 9 years, the youngest of whom was 8 months and the oldest at 17 years old. The 8-month-old infant was an adopted Vietnamese boy whose mother was known to be HBeAg positive but with unknown history of $\mathrm{HBV}$ immunization at birth. There was a male predominance (64\%). The median duration of known HBeAg positivity before first consult was ten months, with a range from six to 96 months. Among the 36, two patients had significant past history: a 17-year-old male who had a previous acute hepatitis B whose HBeAg did not clear after 10 months; and a 12-year-old boy who had concomitant leprosy. Possible modes of infection included vertical in $25(69 \%)$, horizontal in three $(8 \%)$ and unknown route in eight $(23 \%)$ cases. In the majority $(92 \%)$ with possible vertical transmission, the mothers had no prenatal screening and only learned about their HBsAg status later during routine blood test. The three cases with horizontal route of infection had blood transfusion during infancy (2) and at 5 years old (1). The majority (92\%) of patients had completed the three routine doses of HBV vaccination, including a 2-year-old who was given $\mathrm{HBV}$ vaccine and hepatitis $\mathrm{B}$ immunoglobulin at birth.

On admission, no patient had signs or symptoms suggestive of liver disease such as jaundice, hepatomegaly or splenomegaly. All were HBV DNA positive with values from 40 to 110 million IUml. The median ALT and AST levels were $38 \mathrm{IU} / \mathrm{L}$ (13-300) and 35 (16-303) IU/L, respectively. Five patients had at least twice the elevation of their ALT and AST levels ranging from 114 to $303 \mathrm{IU} / \mathrm{L}$. The albumin and prothrombin time were all within normal levels. Twenty eight consented to a liver biopsy in which the degree of portal inflammation was interpreted as minimal in $15(54 \%)$, mild in nine $(32 \%)$ and moderate in four $(14 \%)$. No patient was reported to have fibrosis but one had cirrhosis.

Treatment and outcome. The 36 patients included were followed up from one to 10 (median 5) years from first consult. All patients have remained asymptomatic with normal liver findings on ultrasound and normal levels of alpha feto protein, albumin and international normalized ratio (INR). Of the 36, 14 patients were given anti-viral treatment: 13 with interferon alpha from three to 12 months (median: 6 months) and one with Lamivudine for 12 months on the boy with leprosy. Sustained clearance of HBeAg was noted in six $(43 \%)$ interferon alpha (IFN- $\alpha$ ) treated patients from one to three years after stopping IFN- $\alpha$ and in two (9\%) untreated cases three years from admission into the study. These eight patients remained to have normal transaminase levels and positive for anti-HBe and HBsAg until last follow up including the 17-year-old boy with compensated cirrhosis. The rest of the patients continued to be HBe and HBsAg positive with normal ALT and AST levels. Except for flu-like illness associated with IFN- $\alpha$ treatment and transient leucopenia, no other side effects were noted. No patient has to discontinue IFN- $\alpha$ due to adverse drug reactions.

\section{Discussion}

This 10-year cohort study among Filipino children provides information regarding the demographic and clinical features and medium term outcome of chronic HBV infection acquired in childhood among Filipino children. We showed that perinatal transmission, as seen in most Asian countries, ${ }^{10,11}$ remains an important route of infection in Filipino patients. It is well known that $70-90 \%$ of infants born to HBe and HBsAg positive mothers become chronic carriers of the virus, thus the need to give $\mathrm{HBV}$ vaccine with concomitant HBV immunoglobulin immediately after birth to prevent infection. Although the majority of patients in our study were vaccinated with three doses of HBV vaccine, the initial administration might not have been within the recommended 12 hours after birth, but at a later time following the previous schedule of HBV vaccination starting 
at one month old in our country. In the majority of our vertical cases, the HBsAg status of the mothers was also unknown at the time of birth, thus missing the opportunity to intervene early. In infants born to $\mathrm{HBe} / \mathrm{HBsAg}$ positive mothers, early administration of hepatitis B vaccine with immunoglobulin has a $91-98 \%$ overall efficacy in preventing development of the disease. ${ }^{12,13}$ Fortunately, starting 2005, it has been locally mandated that all infants shall be given immunization against hepatitis B within twelve hours after birth. If this law is strictly implemented, there should be a further decrease in the incidence of hepatitis B in childhood in our country.

Our findings confirm previous reports ${ }^{14}$ that the majority of HBV infected children have no signs or symptoms of chronic liver disease. It is for this reason that identification requires a heightened awareness of the disease. Known risk factors that were seen in our patients were mothers who were $\mathrm{HBe} / \mathrm{HBsAg}$ carriers and history of previous blood transfusion. Maternal-infant transmission occurs mostly as a result of ingestion of maternal blood and vaginal secretions around the time of delivery. ${ }^{15}$ The risk of infection is 25 to $40 \%$ if the mother is HBsAg positive but increases by $90 \%$ if $\mathrm{HBeAg}$ is present. ${ }^{16}$ In the Philippines, it has been shown that the infant's risk of becoming HBsAg positive was 19 times greater $(\mathrm{OR}=18.9,95 \% \mathrm{CI}=2.0-86.6)$ if mothers are $\mathrm{HBsAg}$ positive and 91 times more if mothers are both HBe and HBsAg positive (OR $=91.0,95 \% \mathrm{CI}=49.2$ 164.8). ${ }^{17} \mathrm{HBeAg}$ though is a small viral protein that can cross the placental barrier from the mother to the infant and in $<5 \%$ of cases, infection had been shown to be present at birth, representing intrauterine transmission. ${ }^{18}$ This might explain why one of our patients became a chronic carrier despite the timely administration of $\mathrm{HBV}$ vaccine and immunoglobulin at birth. With regards transfusion as a route of infection, the prevention of transfusion-transmitted $\mathrm{HBV}$ in the Philippines is done using HBsAg alone for routine blood testing of donors. Studies ${ }^{19,20}$ however, have shown that HBV infection may be missed out if the infected blood is within the immunological window period in which HBsAg is no longer detectable. In a local study, screening of 315 apparently healthy blood donors showed that the detection rate for $\mathrm{HBV}$ increased from $3.8 \%$ to $4.4 \%$ using a combination of HBsAg and antibody to core antigen (anti$\mathrm{HBc}$ ) for screening. ${ }^{21}$

Once a child is identified to be a chronic carrier, meaning $\mathrm{HBe} / \mathrm{HBsAg}$ for at least six months, the next step is to decide whether anti-viral treatment will be beneficial with the parents/guardians having a full understanding of the disease and the treatment to be given. One has to consider that the long-term evolution of chronic HBV acquired in childhood does not differ between treated and untreated children. ${ }^{14,22}$ The natural history is characterized by an annual spontaneous $\mathrm{HBeAg}$ clearance rate of $<2 \%$ during the first three years of life but increases by five to $15 \%$ in older children and adolescents. ${ }^{23,24}$ Nonetheless, the main advantage of IFN- $\alpha$ and lamivudine treatment is that it accelerates the $\mathrm{HBeAg}$ seroconversion, therefore decreasing the viral load and possibly the risk of viral integration in the hepatocytes that predisposes to hepatocellular carcinoma. . $^{25,26}$ The duration of treatment is usually between six to 12 months. It is expensive, associated with tolerable side effects and the injection site for IFN- $\alpha$ maybe painful. All patients were offered with antiviral treatment and on the basis of this, 14 patients in our study underwent treatment for a variable period. One patient was given lamivudine, ${ }^{27}$ a viral suppressor, rather than IFN- $\alpha$, as the latter which is an immunomodulator, might cause a flare up of his leprosy. The majority of our treated patients received IFN- $\alpha$ treatment for six months except for three cases: in one, the parents opted to discontinue after three months when HBeAg clearance was achieved with sustained remission; and in two, treatment was extended for another six months after initial HBeAg seroconversion to possibly obtain an HBsAg clearance also. Eight of our patients, six treated and two untreated, were noted to have sustained HBeAg clearance and became anti-HBe positive. None of them however, was able to have a repeat HBV DNA determination because of financial constraints. It has been reported that factors predictive of response to IFN- $\alpha$ treatment ${ }^{28}$ include history of acute hepatitis, significant increase in transaminase levels ( $>2 x$ upper limit of normal), increased inflammatory activity on histology and horizontal rather than a vertical route of infection. The small number of patients in our study will not allow us to identify any of these factors.

To date, there is still no study with sufficiently long term follow up to calculate the risk of progression to serious liver disease among children with chronic HBV although there have been reports of HBV related cirrhosis and hepatocellular carcinoma in childhood.25,26 In our cohort, one patient had cirrhosis on histology. Since no systematic follow up liver biopsy was done, it might well be that progression to cirrhosis might have been missed although ultrasound studies did not reveal any features of serious liver damage and the albumin and INR, which are measures of the liver's synthetic functions, have remained normal. No patient also has developed hepatocellular carcinoma based on normal ultrasound findings and alpha feto protein levels.

In conclusion, this study showed that perinatal transmission remains an important route of chronic HBV infection among Filipino children. All patients were asymptomatic with almost normal liver function tests. The majority had morphologically mild liver disease. One patient had cirrhosis but none had developed hepatocellular carcinoma. In limited cases, IFN- $\alpha$ treatment was observed to accelerate $\mathrm{HBeAg}$ clearance. 


\section{References}

1. Ott JJ, Stevens GA, Groeger J, Wiersma ST. Global epidemiology of hepatitis B virus infection: new estimates of age-specific HBsAg seroprevalence and endemicity. Vaccine. 2012; 30(12):2212-9.

2. Lingao AL, Domingo EO, West $\mathrm{S}$, et al. Seroepidemiology of hepatitis B virus in the Philippines. Am J Epidemiol. 1986; 123(3):473-80.

3. Tiangco-Torres N, Lingao AL, Domingo EO, et al. Hepatitis B virus profile of pregnant and puerperal Filipino women. Philipp J Intern Med. 1984; 22:234-8.

4. Chang $\mathrm{MH}$, Chen $\mathrm{CJ}$, Lai MS, et al. Universal hepatitis B vaccination in Taiwan and the incidence of hepatocellular carcinoma in children. Taiwan Childhood Hepatoma Study Group. N Engl J Med. 1997; 336(26):1855-9.

5. Vajro P, Migliaro F, Fontanella A, Orso G. Interferon: a meta-analysis of published studies in pediatric chronic hepatitis B. Acta Gastroenterol Belg. 1998; 61(2): 219-23.

6. Jonas MM, Mizerski J, Badia IB, et al. Clinical trial of lamivudine in children with chronic hepatitis B. N Engl J Med. 2002; 346(22): 1706-13.

7. Gregorio GV, Jara P, Hierro L, et al. Lymphoblastoid interferon alfa with or without steroid pretreatment in children with chronic hepatitis B: a multicenter controlled trial. Hepatology. 1996; 23(4):700-7.

8. Lai CL, Lin HJ, Lau JN, et al. Effect of recombinant alpha 2 interferon with or without prednisolone in Chinese HBsAg carrier children. Q J Med. 1991; 78(286):155-63.

9. Desmet VJ, Gerber M, Hoofnagle JH, Manns M, Scheuer PJ. Classification of chronic hepatitis: diagnosis, grading and staging. Hepatology. 1994; 19(6):1513-20.

10. Merican I, Guan R, Amarapuka D, et al. Chronic hepatitis B virus infection in Asian countries. J Gastroenterol Hepatol. 2000; 15(12):135661.

11. Wiseman E, Fraser MA, Holden $S$, et al. Perinatal transmission of hepatitis B virus: an Australian experience. Med J Aust. 2009; 190(9):48992.

12. Lee C, Gong Y, Brok J, Boxall EH, Gluud C. Effect of hepatitis B immunisation in newborn infants of mothers positive for hepatitis B surface antigen: systematic review and meta-analysis. BMJ. 2006; 332(7537):328-36.

13. Mackie CO, Buxton JA, Tadwalkar S, Patrick DM. Hepatitis B immunization strategies: timing is everything. CMAJ. 2009; 180(2):196202.

14. Iorio R, Giannattasio A, Cirillo F, D' Alessandro L, Vegnente A. Longterm outcome in children with chronic hepatitis B: a 24-year observation period. Clin Infect Dis. 2007; 45(8):943-9.

15. Yang J, Zeng XM, Men YL, Zhao LS.. Elective caesarean section versus vaginal delivery for preventing mother to child transmission of hepatitis B virus - a systematic review. Virol J. 2008; 5:100.

16. Carey WD. The prevalence and natural history of hepatitis B in the 21st century. Cleve Clin J Med. 2009; 76 Suppl 3: S2-5.

17. Lingao AL, Torres NT, Muñoz N, et al. Mother to child transmission of hepatitis B virus in the Philippines. Infection. 1989; 17(5):275-9.

18. Liu SL, Dong Y, Zhang L, et al. Influence of HBV gene heterogeneity on the failure of immunization with $\mathrm{HBV}$ vaccines in eastern China. Arch Virol. 2009; 154(3):437-43.

19. Stramer SL, Wend U, Candotti D, et al. Nucleic acid testing to detect HBV infection in blood donors. N Engl J Med. 2011; 364(3):236-47.

20. Allain JP, Candotti D; ISBT HBV Safety Collaborative Group. Hepatitis B virus in transfusion medicine: still a problem? Biologicals. 2012; 40(3):180-6.

21. Evangelista KV, Ramirez B. Detection of Hepatitis B Virus (HBV) infection among apparently healthy adults undergoing pre-employment screening a comparison between three Hepatitis B markers: HBV DNA, HbsAg and anti-HBC [abstract]. Acta Med Philipp. 2008; 42(2):73.

22. Bortolotti F, Guido M, Bartolacci S, et al. Chronic hepatitis B in children after e antigen seroclearance: final report of a 29 -year longitudinal study. Hepatology. 2006; 43(3):556-62.

23. Fattovich G. Natural history of hepatitis B. J Hepatol. 2003; 39 Suppl 1:S50-8.
24. Lee WM. Hepatitis B virus infection. N Engl J Med. 1997; 337(24):173345 .

25. Chang MH, Chen PJ, Chen JY, et al. Hepatitis B virus integration in hepatitis B virus-related hepatocellular carcinoma in childhood. Hepatology. 1991; 13(2):316-20.

26. Ni YH, Chang MH, Wang KJ, et al. Clinical relevance of hepatitis B virus genotype in children with chronic infection and hepatocellular carcinoma. Gastroenterology. 2004; 127(6):1733-8.

27. Sokal EM, Roberts EA, Mieli-Vergani G, et al. A dose ranging study of the pharmacokinetics, safety and preliminary efficacy of lamivudine in children and adults with chronic hepatitis B. Antimicrob Agents Chemother. 2000; 44(3):590-7.

28. Shah U, Kelly D, Chang MH, et al. Management of chronic hepatitis B in children. J Pediatr Gastroenterol Nutr. 2009; 48(4):399-404. 